\title{
The impact of COVID-19 pandemic on headache symptoms and drug withdrawal among patients with medication overuse headache: a cross-sectional study
}

Changling $\mathrm{Li}^{\dagger}$, Yanbo Li ${ }^{\dagger}$, Mengmeng Ma, Yang Zhang, Jiajia Bao, Wenjing Ge, Yanqin Liu, Cheng Peng and $\mathrm{Li} \mathrm{He}^{*}$ (iD)

\begin{abstract}
Background: Coronavirus disease 2019 (COVID-19) bring about a range of psychological distress and symptom deterioration to headache patients especially to some migraineurs. Compared to migraineurs or normal control, medication overuse headache $(\mathrm{MOH})$ patients are more likely to experience a worse psychological distress and poorer outcome in non-COVID-19 time. However, in COVID-19 pandemic, whether MOH patients would have greater physical and mental symptom deterioration or worse relief of headache symptoms and medications overuse remained unclear. We aim to investigate the impact of COVID-19 on MOH patients to guide for a better management in this study.
\end{abstract}

Methods: We enrolled $\mathrm{MOH}$ patients who were diagnosed and treated at headache clinic of West China Hospital. Information of the pre-pandemic 3 months period and COVID-19 pandemic period was collected. Univariate and multivariate logistic regression were performed to identify independent factors associated with changes in headache symptoms and drug withdrawal.

Results: Seventy-eight $\mathrm{MOH}$ patients were enrolled into the study ultimately. In comparison to pre-pandemic period, fewer $\mathrm{MOH}$ patients reported decreased headache days, intensity and days with acute medications per month during the pandemic. Available access to regular prophylactic medications was significantly associated with a reduction of at least $50 \%$ in headache days and decrease in headache intensity per month with respective odds ratios of 39.19 (95\% Cl 3.75-409.15, $P=0.002$ ) and $10.13(95 \% \mathrm{Cl} 2.33-44.12, \mathrm{P}=0.002)$. Following abrupt withdrawal and high educational level were both significant factors in decreasing headache intensity. Male sex was significantly associated with decrease in days with acute medication per month during the pandemic (odds ratios $4.78,95 \% \mathrm{Cl}$ $1.44-15.87, P=0.011)$.

\footnotetext{
* Correspondence: heli2003new@126.com

${ }^{\dagger}$ Changling Li and Yanbo Li contributed equally to this work and should be considered as co-first authors.

Department of Neurology, West China Hospital of Sichuan University, No. 37 Wainan Guoxue Xiang, Chengdu 610041, China
}

(c) The Author(s). 2021 Open Access This article is licensed under a Creative Commons Attribution 4.0 International License, which permits use, sharing, adaptation, distribution and reproduction in any medium or format, as long as you give appropriate credit to the original author(s) and the source, provide a link to the Creative Commons licence, and indicate if changes were made. The images or other third party material in this article are included in the article's Creative Commons licence, unless indicated otherwise in a credit line to the material. If material is not included in the article's Creative Commons licence and your intended use is not permitted by statutory regulation or exceeds the permitted use, you will need to obtain permission directly from the copyright holder. To view a copy of this licence, visit http://creativecommons.org/licenses/by/4.0/ The Creative Commons Public Domain Dedication waiver (http://creativecommons.org/publicdomain/zero/1.0/) applies to the data made available in this article, unless otherwise stated in a credit line to the data. 
Conclusions: Our findings reflect that $\mathrm{MOH}$ patients experienced a worse relief of headache symptoms and drug withdrawal during the pandemic. Available access to regular prophylactic medications was the significant independent factor for improvement of headache symptoms. Male sex was significantly associated with decreased days with acute medications per month.

Keywords: COVID-19, Pandemic, Medication overuse headache, Prophylactic, Withdrawal

\section{Introduction}

Coronavirus disease 2019 (COVID-19) caused by severe acute respiratory syndrome coronavirus 2 (SARS-CoV-2) [1] has already rapidly spread around the world as a pandemic after its first report in Wuhan, China on December 12th 2019 [2-5]. As of December 27th 2020, there were more than 79.2 million confirmed cases and more than 1.7 million deaths caused by COVID-19 worldwide [6]. The outburst of high contagious and deadly COVID-19 lead to a period of protective equipment insufficiency and prompted the execution of the policies of home quarantine and social isolation. These are all considered to bring about a range of psychological distress among the public [7]. For patients with chronic neurological diseases, such as multiple sclerosis, neurodegenerative disease, chronic headache and etc., they were considered to probably experience psychological distress such as despair or depression under the impact of the COVID-19 pandemic as Bhaskar stated, which resulted in non-compliance, potential relapse and worsening of the condition [8].

Medication overuse headache $(\mathrm{MOH})$ is an important secondary chronic headache disorder which gets little attention. It is caused by long-term regular overuse of analgesics or acute medications in patients suffering from primary headache disorders such as migraine and tension-type headache (TTH) or other secondary headaches [9-11]. Globally, MOH makes an influence on approximately 60 million people, ranking one of the global top 20 causes of disability [12] and resulting in significant socioeconomic consequences [13-16]. It is a troublesome disease that requires more medical care and regular follow-up because of its relatively high relapse rate [10].

In non-COVID-19 time, $\mathrm{MOH}$ patients are more likely to comorbid with psychological distress (including depression and anxiety) than normal population and migraineurs, and the psychological distress is tightly associated with poor outcomes of withdrawal therapy among $\mathrm{MOH}$ patients [9, 17-22].

Whereas, after COVID-19 burst out, migraineurs were reported to have had suffered increased migraine frequency and pain intensity as well as overuse of analgesics and acute migraine treatments, due to high levels of psychosocial distress and COVID-19-related concerns $[23,24]$. Thus, like the phenomenon we observe under
non-COVID-19 circumstances, we considered that $\mathrm{MOH}$ patients might be inclined to experience a greater symptom deterioration or worse relief of the condition than migraineurs did under the impact of the COVID19 pandemic. However, what $\mathrm{MOH}$ patients actually suffered during the pandemic remained unclear.

Thus, in this cross-sectional study, we aimed to investigate the change and relevant factors of headache days, headache intensity, and days with acute medication per month in $\mathrm{MOH}$ patients during the COVID-19 pandemic, compared by those in pre-pandemic period, to provide guides for the management of $\mathrm{MOH}$ patients during the time attacked by this public health emergency.

\section{Methods and materials}

This cross-sectional study was conducted in forms of telephone surveys on $\mathrm{MOH}$ patients who were recruited from the headache database between April and July, 2020. We used a designed questionnaire containing several validated scales to obtain the information about headache symptoms, psychosocial status and therapeutic condition of the $\mathrm{MOH}$ group in its pre-pandemic 3 months period and COVID-19 pandemic period. This telephone-based questionnaire ended in July, 2020.

\section{Participants}

We recruited patients who were diagnosed with $\mathrm{MOH}$ according to the International Classification of Headache Disorders, 3rd edition (ICHD-III) criteria [25] from a tertiary headache clinic of West China Hospital. Patients were identified from an existing database with the age beyond 18 years old. Routinely, they were followed up monthly by a neurology specialist once they were incorporated into our database. The patients we followed were receiving $\mathrm{MOH}$ treatments, and some had been overuse-free while others had stayed overused in prepandemic 3 months period. Patients were excluded if they were confirmed COVID-19-positive patient; or they had a history of psychiatric disorders; or they were unwilling to receive telephone interview or unable to complete the questionnaires.

The study was reviewed by the Ethics Committee of West China Hospital, Sichuan University, and verbal informed consent was provided by all participants. 


\section{Data collection}

The telephone-based study was conducted by two neurologists who did not know the purpose of the study. The following items were included in the questionnaire:

(1) Demographic variables (sex, age, marital status, living with others, educational level, and household income monthly). (2) $\mathrm{MOH}$ related information of pre-pandemic 3 months period and COVID-19 pandemic period (preexisting headache, duration of medication overuse, available access to regular prophylactic medications, headache days per month, headache intensity [Visual Analogue Scale score with range of 0-10] per month, days per month with acute medication, and Migraine Disability Assessment Scale [MIDAS] score). (3) COVID-19 related information (epidemiological area exposure history, suspected COVID-19 cases themselves or in their relatives, COVID-19 cases in respondent's residential community, feel of difficulty in controlling emotions, frequency of COVID-19 related dreams, duration per day spent on following news of COVID-19 pandemic, level of concern about the pandemic [4 points scales from "relatively unconcerned or very unconcerned" to "very concerned"], psychological disorder history, psychological distress during the COVID-19 pandemic [Mandarin version of Kessler 6-item psychological distress scale (K-6 scale) [26]], and COVID-19 related stressor investigation scale).

Psychological distress during the COVID-19 pandemic was measured by using K-6 scale, which was designed by Kessler et al. It was frequently used in large-scale surveys to assess non-specific psychological distress over the past month [27, 28]. The scale includes 6 items: "nervous", "hopeless", "restless or fidgety", "so depressed that nothing could cheer you up", "everything is an effort" and "worthless" [27]. The Link 5 score is applied for each item, "0" means none of the time, " 1 " means a little of the time, " 2 " means some of the time, " 3 " means most of the time, and "4" means all the time [29]. K-6 total score $>12$ was considered a severe psychological stress and the mandarin version has been proven to have good reliability and validity [26].

COVID-19 related stressor was assessed by using a self-designed stressor scale based on the study of Kerang Zhang et al. during the pandemic of SARS (Severe Acute Respiratory Syndrome). The scale was divided into 7 aspects, including 18 items: (1) Fear for getting COVID-19 (4 items): including yourself, family members, friends and colleagues. (2) Physical and psychological distress caused by isolation ( 2 items). (3) Inconvenience caused by work and life changes during COVID-19 pandemic (2 items). (4) Social discrimination (2 items): including subjective feelings and objective facts. (5) Limited social function (4 items): including school enrollment, employment, making friends, wedding, interpersonal communication and other aspects. (6) Economic losses (2 items): temporary and long-term economic losses. (7) Coronavirus death of family members or friends ( 2 items). The Link 5 score is performed for each item, "1" means completely inconsistent, "2" means less inconsistent, "3" means general, "4" means more consistent, and "5" means completely consistent. The score of 2 for each item indicates that patients were mildly affected in this item. The higher the score, the more severe the response to stress induced by COVID-19 pandemic was.

In this study, the main outcomes were set as changes in headache days, headache intensity and days with acute medication per month from 3 months pre-pandemic to COVID-19 pandemic. We used reduction of at least 50\% to illustrate the change in headache days per month, and reduction of at least $50 \%$ in headache days per month was defined as improvement in headache days among $\mathrm{MOH}$ patients [30]. In addition, relevant factors were also analyzed for these changes among $\mathrm{MOH}$ patients.

\section{Statistical analysis}

Statistical Product and Service Solutions (SPSS) Software 22.0 (SPSS Inc., Chicago, IL, USA) for Windows was used for data analysis. Continuous variables were represented by means and standard deviation or median and percentile, and categorical variables were represented by absolute numbers and percentages. Univariate logistic regression was performed to determine the association between the clinical variables and change in headache days, headache intensity and days with acute medication per month. Multivariate logistic regression was used to explore factors which were independently associated with the change. Variables associated with $P<0.10$ in the univariate analysis and covariates of interest in previous articles were incorporated in the multivariate regression model by using the enter method.

All tests were two-sided and $P<0.05$ was considered statistically significant.

\section{Results}

One hundred and ten patients with $\mathrm{MOH}$ were invited to participate in the questionnaire survey, 26 patients rejected the interview or were unable to complete the questionnaires; 6 patients were excluded because they had mental disease currently or before. In the end, 78 $\mathrm{MOH}$ patients $(70.9 \%)$ were enrolled.

\section{Demographic and clinical characteristics}

Among all the 78 enrolled patients, the mean age was $51.6( \pm 10.5)$ years, and a total of $28(35.9 \%)$ patients with $\mathrm{MOH}$ were male sex. The majority of the patients were married (93.6\%) and living with others (84.6\%). Lower educational level and lower monthly household income 
were reported by most patients (Table 1 ). Besides, episodic migraine and TTH were present in $50 \%(39 / 78)$ of the preexisting headache diagnoses, and the median duration of medication overuse was $3.0(2.0-7.3)$ years. Available access to regular prophylactic medications only occurred in $41.0 \%(32 / 78)$ patients during the pandemic. Less than $50 \%$ patients followed abrupt withdrawal. The MIDAS score was low during the pandemic with the median score of $0.0(0.0-7.0)$.

\section{COVID-19 related information}

Less than $3 \%$ of the patients reported previous epidemiological area exposure or recent community exposure to COVID-19 cases (eg. sharing an environment with COVID-19 cases in the same residential community). One of the patients was ever considered to be suspected COVID-19 patient, however, he was ultimately confirmed to be COVID-19-free before our survey. Few patients had difficulty in controlling emotion and no one had COVID-19 related dreams. The duration spent on following COVID-19 pandemic news was also low with mean of $0.6( \pm 1.1)$ hours per day, and more than half of the patients were relatively unconcerned or very unconcerned about the pandemic. In addition, on basis of the stressor scale, $\mathrm{MOH}$ patients were found to be affected, to a minor degree, by multiple COVID-19 related aspects excluding the item of COVID-19 death. The mean score of the overall stressors was $30.8( \pm 10.0)$ (shown in Table 1). Psychological distress evaluated by K-6 was low in all the patients with the median score of $1.0(0.0-$ 3.0) and no one experienced severe psychological distress.

\section{Main outcomes}

Compared to pre-pandemic period, headache days per month unchanged in more than half of patients (53.8\%), and increased in $16.7 \%(13 / 78)$ of patients during the pandemic. Only $20.5 \%(16 / 78)$ of the patients reported a reduction of $50 \%$ or more in headache days per month (Table 2).

With regard to the headache intensity per month, 8 (10.3\%) patients reported increased headache intensity and $43(55.1 \%)$ patients remained unchanged during the pandemic. Left 27 (34.6\%) patients experienced decreased headache intensity per month (Table 2).

Similar changes were observed in the outcome of days per month with acute medication (Table 2). During the pandemic, $71.0 \%(22 / 31)$ of the original overusers still overused acute medications and $29.0 \%$ of them were overuse-free. Meanwhile, $89.4 \%$ (42/47) of the original non-overusers remained overuse-free and $10.6 \%$ of them overused acute medications again $(P<0.001)$.
Assessment of the relevant factors associated with a reduction of at least $50 \%$ in headache days per month The univariate logistic analysis showed that available access to regular prophylactic medications and following abrupt withdrawal were significantly associated with the reduction of at least $50 \%$ in headache days per month $(P<0.05$, Table 3$)$. Multivariate logistic regression showed that available access to regular prophylactic medications was an independent predictor for a reduction of at least $50 \%$ in headache days per month with OR of 39.19 during the COVID-19 pandemic (95\% CI 3.75-409.15, $P=0.002$; Table 3).

\section{Assessment of the relevant factors associated with decrease in headache intensity per month}

Available access to regular prophylactic medications and following abrupt withdrawal were significantly associated with decrease in headache intensity per month in the univariate logistic regression $(P<0.05$, Table 4$)$. Available access to regular prophylactic medications (OR 10.13, 95\% CI 2.33-44.12, $P=0.002$ ), following abrupt withdrawal (OR 5.12, 95\% CI 1.27-20.54, $P=0.021$ ) and high educational level (OR 5.98, 95\% CI 1.19-30.06, $P=$ 0.030 ) were significantly associated with decrease in headache intensity per month when potential factors were incorporated into the multivariate logistic regression model (Table 4).

\section{Assessment of the relevant factors associated with decrease in days per month with acute medication} Male sex was significantly associated with the decrease in days per month with acute medication in univariate logistic analysis $(P=0.021$, Table 5). Multivariate logistic regression showed that male sex was a significant independent factor for the decrease in days per month with acute medication with OR of 4.78 (95\% CI 1.44-15.87, $P=0.011$; Table 5).

\section{Discussion}

$\mathrm{MOH}$ is often overlooked despite its heavy disease burden, and currently it is more widely recognized as a separate diagnostic entity secondary to a pre-existing headache disorder in the ICHD-III [11]. Since MOH patients are more likely to suffer from psychological distress and easy to have bad outcome, headache specialists need to pay more attention to them, especially during the COVID-19 pandemic. We conducted this study to investigate the change in headache days, headache intensity, days with acute medication per month and their relevant factors among $\mathrm{MOH}$ patients from 3 months pre-pandemic to COVID-19 pandemic for a better management. Few $\mathrm{MOH}$ patients in pandemic period had decreased headache intensity, decreased days with acute medications, and a reduction of at least $50 \%$ in headache 
Table 1 Distribution of different variables in $\mathrm{MOH}$ patients

\begin{tabular}{ll}
\hline Characteristic & $\begin{array}{l}\text { MOH patients } \\
(\boldsymbol{n}=\mathbf{7 8})^{*}\end{array}$ \\
\hline Sex, male & $28(35.9 \%)$ \\
Age, year & $51.6 \pm 10.5$ \\
Marital status, married & $73(93.6 \%)$ \\
Living with others & $66(84.6 \%)$ \\
Education level, year & \\
$\quad \leq 12$ & $64(82.1 \%)$ \\
$>$ 12 & $14(17.9 \%)$ \\
Household income monthly ${ }^{\text {a }}$, RMB & \\
0-4999 & $41(52.5 \%)$ \\
5000-9999 & $22(28.2 \%)$ \\
10,000-14,999 & $8(10.3 \%)$ \\
15,000-19,999 & $3(3.9 \%)$ \\
$>$ 20,000 & $4(5.1 \%)$ \\
Preexisting headache diagnoses & \\
Chronic migraine & $5(6.4 \%)$ \\
Episodic migraine and THH & $39(50.0 \%)$ \\
Chronic TTH & $34(43.6 \%)$ \\
Duration of medication overuse, year & $3.0(2.0-7.3)$ \\
Available access to regular prophylactic medications & $32(41.0 \%)$ \\
mollowing abrupt withdrawal & $34(43.6 \%)$ \\
Headache intensity per month in the pre-pandemic period & $10.0(3.0-18.5)$ \\
\hline
\end{tabular}

Days per month with acute medication in the pre- 10.0 (1.0-15.0) pandemic 3 months period

$\begin{array}{ll}\text { MIDAS score during the COVID-19 pandemic } & 0.0(0.0-7.0) \\ \text { History of epidemiological area exposure } & 2(2.6 \%) \\ \begin{array}{l}\text { Suspected COVID-19 cases themselves or in their } \\ \text { relatives }\end{array} & 1(1.3 \%) \\ \text { COVID-19 cases in respondent's residential } & 2(2.6 \%)\end{array}$

Level of concern about COVID-19 pandemic

$\begin{array}{ll}\text { Very concerned } & 4(5.1 \%) \\ \text { Concerned } & 22(28.2 \%) \\ \text { Average } & 11(14.1 \%) \\ \text { Relatively unconcerned or very unconcerned } & 41(52.6 \%) \\ \begin{array}{l}\text { Duration spent on following news of pandemic, } \\ \text { hours per day }\end{array} & 0.6 \pm 1.1 \\ \begin{array}{l}\text { Feel of difficulty in controlling emotion during the } \\ \text { COVID-19 pandemic }\end{array} & 6(7.7 \%) \\ \text { Frequency of COVID-19 related dreams } & \\ \text { Most of time or sometimes } & 0 \\ \text { None } & 78(100.0 \%) \\ \text { Stressors total score during the COVID-19 pandemic } & 30.8 \pm 10.0 \\ \text { Fear for getting COVID-19 (4 items) } & 6.9 \pm 3.1\end{array}$

Table 1 Distribution of different variables in $\mathrm{MOH}$ patients (Continued)

\begin{tabular}{ll}
\hline Characteristic & $\begin{array}{l}\text { MOH patients } \\
(\boldsymbol{n}=\mathbf{7 8})\end{array}$ \\
\hline $\begin{array}{l}\text { Physical and psychological distress caused by } \\
\text { isolation (2 items) }\end{array}$ & $3.0 \pm 1.9$ \\
$\begin{array}{l}\text { Inconvenience caused by work and life changes } \\
(2 \text { items) }\end{array}$ & $3.7 \pm 2.6$ \\
Social discrimination (2 items) & $2.1 \pm 0.6$ \\
Limited social function (4 items) & $8.9 \pm 4.3$ \\
Economic losses (2 items) & $4.2 \pm 2.5$ \\
Coronavirus death of family members or friends (2 & $2.0 \pm 0.1$ \\
items) & \\
Kessler 6-item psychological distress scale during & $1.0(0.0-3.0)$ \\
the COVID-19 pandemic & \\
Nervous & $0.0(0.0-1.0)$ \\
Hopeless & $0.0(0.0-0.0)$ \\
Restless or fidgety & $0.0(0.0-1.0)$ \\
So depressed that nothing could cheer you up & $0.0(0.0-1.0)$ \\
Everything is an effort & $0.0(0.0-0.0)$ \\
Worthless & $0.0(0.0-0.0)$ \\
Severe psychological distress & 0 \\
\hline *Values are $\mathrm{n}$ (\%), mean \pm SD, or median (quartiles) & \\
a: 1 RMB $=0.141$ USD on 30 June 2020 &
\end{tabular}

days per month. We found that available access to regular prophylactic medications was significantly associated with improvement of headache symptoms. Meanwhile, higher educational level and following abrupt withdrawal were significant independent factors for decreased headache intensity per month. Male sex was significantly associated with decrease in days with acute medication per month.

During the pandemic, we found few $\mathrm{MOH}$ patients experiencing improved headache days and intensity compared with pre-pandemic period. These results differ from the findings of several published studies conducted in $\mathrm{MOH}$ patients under non-COVID-19 condition [14, $17,31,32]$, which found significant decrease in headache days and intensity per month in most $\mathrm{MOH}$ patients with regular prophylactic medications. The inconsistency is probably due mainly to the difficulty of accessing to regular prophylactic medications during the pandemic on basis of our analysis. In the present study, only $41.0 \%$ of $\mathrm{MOH}$ patients could obtain regular prophylactic medications during the pandemic, while in the previous studies the majority of $\mathrm{MOH}$ patients could receive regular and timely prophylactic medications. On one hand, all the resources became strained and supplements and medical services were reconfigured to meet the demands of fighting for COVID-19 in the midst of pandemic. About half of the patients with chronic diseases were unable to receive regular medications during the 
Table 2 Outcome changes during COVID-19 pandemic in $\mathrm{MOH}$ patients

\begin{tabular}{ll}
\hline Outcome & MOH patients \\
\hline Change in headache days per month & $13(16.7 \%)$ \\
Increase & $42(53.8 \%)$ \\
Unchanged & $23(29.5 \%)$ \\
Decrease & $16(20.5 \%)$ \\
$50 \%$ reduction & \\
Change in headache intensity per month & $8(10.3 \%)$ \\
Increase & $43(55.1 \%)$ \\
Unchanged & $27(34.6 \%)$ \\
Decrease & \\
Change in days per month with acute medication & $11(14.1 \%)$ \\
Increase & $46(59.0 \%)$ \\
Unchanged & $21(26.9 \%)$ \\
Decrease & $9(11.5 \%)$ \\
Change from medication overuse to non-overuse &
\end{tabular}

aalues are $\mathrm{n}(\%)$, mean \pm SD

pandemic as the World Health Organization stated from a survey conducted in 155 countries [33]. On the other hand, the social distancing and the lockdown have critically affected the ongoing care, access and support of outpatients [7]. Especially for chronic headache [8] including $\mathrm{MOH}$ patients, stress is increasing on giving them the regular medical care and medications in the drearier light of COVID-19.

Available access to regular prophylactic medications was significantly associated with the reduction of at least $50 \%$ in headache days and decreased headache intensity per month during the pandemic. The finding was consistent with the previous study of Diener et al. who found that receiving regular prophylactic medications could lead to a reduction in headache days and headache intensity among $\mathrm{MOH}$ patients in non-COVID-19 time [9]. Besides, following abrupt withdrawal was also the independent factor for decreased headache intensity in our study. The results showed that as the fact in nonCOVID-19 time [14, 31, 34] combined therapy of abrupt withdrawal with prophylactic medications could also decrease headache days and headache intensity per month in $\mathrm{MOH}$ patients during the COVID-19 pandemic. As a series of current guidelines and authors recommended, receiving withdrawal with simultaneous prophylactic medications is the most effective treatment for the $\mathrm{MOH}$ patients $[31,35,36]$. According to patient compliance, different withdrawal approaches were applied in $\mathrm{MOH}$ patients, but abrupt withdrawal was demonstrated to be more effective than tapered withdrawal based on a randomized study [37]. Similarly, our study found that abrupt withdrawal independently affected the headache outcome, which showed that abrupt withdrawal might be an appropriate approach for $\mathrm{MOH}$ patients to get an effective headache relief during the pandemic. Hence, available access to regular prophylactic medications and following abrupt withdrawal were likely to be important factors influencing the management of $\mathrm{MOH}$ patients during the pandemic. We could be able to improve headache symptoms of $\mathrm{MOH}$ patients by adjusting for these factors. High educational level was also significantly correlated to decreased headache intensity in this study. $\mathrm{MOH}$ patients with a higher educational level tended to be more willing to use prophylactic medications or consult neurologists than those with a lower educational level [38]. The higher educational level patients had, the more likely they were to obtain and follow education programs and guidelines of $\mathrm{MOH}$ managements, and thus to decrease headache intensity.

Headache specialists should pay particular attention to $\mathrm{MOH}$ patients with low educational level during the pandemic. They could make use of the telephone or telemedicine to conduct follow-up for $\mathrm{MOH}$ patients and maintain continuity of withdrawal and prophylactic medications through delivering medications to $\mathrm{MOH}$ patients' home when they collaborated with commercial courier services.

As for days with acute medications per month, the majority of $\mathrm{MOH}$ patients reported unchanged or increased days with acute medication per month while fewer patients reported decreased days during the pandemic. Moreover, more than $70 \%$ of the original overusers still overused acute medications. In non-COVID-19 time, more than $60 \%$ of $\mathrm{MOH}$ patients were overuse free when treated by withdrawal combined with prophylactic medications in a multicenter and multinational study [35]. A possible explanation for this difference might be that $\mathrm{MOH}$ patients altered their drug administration passively or positively on their own. During the COVID19 pandemic, regular prophylactic medications were difficult to access for $\mathrm{MOH}$ patients because of the inconveniences on transportation, seeking medical advice and so on, while acute medications were easy to get due to their ready accessibility (without prescription) and bargain price (average CNY 0.055 per tablet) as reported in China [32]. In our study, we found only $43.6 \%$ of $\mathrm{MOH}$ patients were able to follow the abrupt withdrawal and others were not able to. Although the tapered withdrawal could relieve withdrawal symptoms and improve patient acceptance by allowing restricted intake of acute medication during withdrawal $[35,39]$, patients with this tapered withdrawal approach were more psychologically dependent on headache acute medications than those with abrupt withdrawal at follow-up, and they might be less likely to complete the withdrawal [40]. Hence, some $\mathrm{MOH}$ patients with frequent headache attacks might be less willing to follow the abrupt withdrawal approach as 
Table 3 Univariate and multivariate logistic analysis to identify independent variables reducing headache days ( $\geq 50 \%)$

\begin{tabular}{|c|c|c|c|c|}
\hline \multirow[t]{2}{*}{ Variables } & \multicolumn{2}{|l|}{ Univariate } & \multicolumn{2}{|l|}{ Multivariate } \\
\hline & OR(95\%Cl) & $\mathbf{P}$ & $\mathrm{OR}(95 \% \mathrm{Cl})$ & $\mathbf{P}$ \\
\hline Sex, male & $2.1(0.69-6.41)$ & 0.192 & - & - \\
\hline Age, year & $1.03(0.97-1.09)$ & 0.329 & - & - \\
\hline Marital status, married & $1.03(0.11-9.95)$ & 0.997 & - & - \\
\hline Education level (> 12 years) & $1.07(0.26-4.40)$ & 0.925 & - & - \\
\hline Household income monthly & $1.14(0.38-3.42)$ & 0.818 & - & - \\
\hline Preexisting headache diagnoses (CTTH vs. others) & $0.73(0.24-2.25)$ & 0.582 & $0.50(0.09-2.82)$ & 0.434 \\
\hline Duration of medication overuse & $0.90(0.76-1.05)$ & 0.182 & - & - \\
\hline Available access to regular prophylactic medication & $39.71(4.86-324.16)$ & $0.001^{*}$ & $39.19(3.75-409.15)$ & $0.002^{*}$ \\
\hline Following abrupt withdrawal & $5.46(1.57-18.95)$ & $0.008^{*}$ & $3.47(0.65-18.59)$ & 0.147 \\
\hline Headache days per month in the pre-pandemic 3 months period & $1.00(0.95-1.05)$ & 0.953 & $1.06(0.91-1.22)$ & 0.469 \\
\hline Days per month with acute medication in the pre-pandemic 3 months period & $0.98(0.93-1.03)$ & 0.448 & $0.96(0.84-1.10)$ & 0.532 \\
\hline History of epidemiological area exposure & $0.25(0.02-4.16)$ & 0.331 & - & - \\
\hline Suspected COVID-19 cases themselves or in their relatives & - & 1.000 & - & - \\
\hline COVID-19 cases in respondent's residential community & $0.25(0.02-4.16)$ & 0.331 & - & - \\
\hline Level of concern about COVID-19 pandemic & $1.56(0.52-4.72)$ & 0.430 & - & - \\
\hline Duration spent on following news of pandemic & $1.65(0.91-2.98)$ & 0.099 & $1.23(0.65-2.32)$ & 0.527 \\
\hline Feel of difficulty in controlling emotion during the COVID-19 pandemic & $2.07(0.34-12.49)$ & 0.426 & - & - \\
\hline Stressors total score during the COVID-19 pandemic & $1.02(0.97-1.08)$ & 0.409 & - & - \\
\hline Fear for getting COVID-19 & $0.96(0.80-1.16)$ & 0.680 & - & - \\
\hline Physical and psychological distress caused by isolation & $1.13(0.86-1.47)$ & 0.390 & $1.08(0.69-1.70)$ & 0.731 \\
\hline Inconvenience caused by work and life changes & $1.02(0.83-1.25)$ & 0.870 & $1.18(0.83-1.68)$ & 0.355 \\
\hline Social discrimination & - & 0.999 & - & - \\
\hline Limited social function & $1.07(0.94-1.21)$ & 0.305 & - & - \\
\hline Economic losses & $1.17(0.95-1.45)$ & 0.144 & - & - \\
\hline Coronavirus death of family members or friends & - & 1.000 & - & - \\
\hline Kessler 6-item psychological distress scale during the COVID-19 pandemic & $0.89(0.69-1.15)$ & 0.356 & - & - \\
\hline
\end{tabular}

$\mathrm{Cl}$ Confidence interval; *: Statistically significant at $P<0.05$

they did in non-COVID-19 time [10] and still remained medication overuse especially when they did not receive regular prophylactic medications during the pandemic. Therefore, we should pay more attention to $\mathrm{MOH}$ patients' health education and work to provide appropriate consultation for them if they followed the tapered withdrawal approach [31], by which we strived to help them effectively reduce the intake of acute medication during the pandemic.

We found male sex was significantly associated with decreased days with acute medication per month during the pandemic. Previously, no evidence was provided to support the positive correlation between male sex and acute medication administration. In our study, the cause of the sex differences in acute medication administration might come down to the following aspect. We found that psychological distress was lower in male sex than in female sex although it was not statistically significant.
Compared with female sex, male sex was shown to be more inclined to have high resilience, a conception to reflect the good adaptation in the face of adversity, trauma, or even significant sources of stress [41]. This kind of high resilience in male sex might decrease the risk of medication overuse by relieving the psychological distress themselves during the pandemic [42-45]. Closer monitor on female patients was warranted about their acute medication intake per month in the therapeutic activity.

Furthermore, for psychological evaluation, none of the $\mathrm{MOH}$ participants in our study was found to suffer severe psychological distress indicated by K-6 scale during the COVID-19 pandemic surprisingly. Several reasons might account for this result. At first, hardly any recruited patients had epidemiological area exposure history and had COVID-19 cases in their community. Most of them were relatively unconcerned about the pandemic 
Table 4 Univariate and multivariate logistic analysis to identify independent variables decreasing headache intensity per month

\begin{tabular}{|c|c|c|c|c|}
\hline \multirow[t]{2}{*}{ Variables } & \multicolumn{2}{|l|}{ Univariate } & \multicolumn{2}{|l|}{ Multivariate } \\
\hline & $\mathrm{OR}(95 \% \mathrm{Cl})$ & $\mathbf{P}$ & OR(95\%Cl) & $\mathbf{P}$ \\
\hline Sex, male & $1.08(0.41-2.84)$ & 0.879 & - & - \\
\hline Age, year & $1.00(0.96-1.05)$ & 0.965 & - & - \\
\hline Marital status, married & $0.33(0.05-2.09)$ & 0.237 & - & - \\
\hline Education level (> 12 years) & $3.16(0.96-10.34)$ & 0.058 & $5.98(1.19-30.06)$ & $0.030^{*}$ \\
\hline Preexisting headache diagnoses (CTTH vs. others) & $1.06(0.41-2.70)$ & 0.912 & $2.05(0.49-8.50)$ & 0.323 \\
\hline Duration of medication overuse & $0.87(0.75-1.00)$ & 0.051 & $0.90(0.76-1.06)$ & 0.192 \\
\hline Available access to regular prophylactic medication & $5.29(1.93-14.50)$ & $0.001^{*}$ & $10.13(2.33-44.12)$ & $0.002^{*}$ \\
\hline Following abrupt withdrawal & $4.38(1.62-11.83)$ & $0.004^{*}$ & $5.12(1.27-20.54)$ & $0.021^{*}$ \\
\hline Headache intensity per month in the pre-pandemic 3 months period & $1.11(0.90-1.37)$ & 0.314 & $1.12(0.84-1.50)$ & 0.449 \\
\hline History of epidemiological area exposure & - & 0.999 & - & - \\
\hline Suspected COVID-19 cases themselves or in their relatives & - & 1.000 & - & - \\
\hline COVID-19 cases in respondent's residential community & $0.52(0.03-8.66)$ & 0.649 & - & - \\
\hline Level of concern about COVID-19 pandemic & $2.08(0.81-5.37)$ & 0.131 & - & - \\
\hline Duration spent on following news of pandemic, hours per day & $1.50(0.86-2.63)$ & 0.154 & - & - \\
\hline Feel of difficulty in controlling emotion during the COVID-19 pandemic & $0.94(0.16-5.49)$ & 0.945 & - & - \\
\hline Stressors total score during the COVID-19 pandemic & $1.02(0.97-1.07)$ & 0.393 & - & - \\
\hline Fear for getting COVID-19 & $1.01(0.87-1.17)$ & 0.913 & - & - \\
\hline Physical and psychological distress caused by isolation & $0.99(0.77-1.28)$ & 0.965 & $0.78(0.54-1.12)$ & 0.175 \\
\hline Inconvenience caused by work and life changes & $1.12(0.94-1.33)$ & 0.198 & $1.32(1.00-1.73)$ & 0.051 \\
\hline Social discrimination & $1.14(0.54-2.41)$ & 0.727 & - & - \\
\hline Limited social function & $1.03(0.92-1.15)$ & 0.584 & - & - \\
\hline Economic losses & $1.10(0.91-1.32)$ & 0.332 & - & - \\
\hline Coronavirus death of family members or friends & - & 1.000 & - & - \\
\hline Kessler 6-item psychological distress scale during the COVID-19 pandemic & $0.96(0.80-1.16)$ & 0.672 & - & - \\
\hline
\end{tabular}

CI Confidence interval; *: Statistically significant at $P<0.05$

and spent little time following news of pandemic through social media. However, longer time of social media exposure was demonstrated be associated with the increased risk of psychological distress [46]. This could be the reason why the participants did not get distressed. Next, the resilience could be an important inner strength to weaken psychological distress during the pandemic $[43,44]$. Riehm et al. found that middle-aged and older ( $\geq 50$ years) adults tended more to report high resilience during the pandemic [45]. In our study, the mean age of the $\mathrm{MOH}$ participants was $51.6( \pm 10.5)$ year-old. We had reason to believe that most people in this group may be highly resilient to this the changes caused by COVID-19, showing a status with only mild psychological distress. Furthermore, although K-6 scale is a widely used scale for non-specific psychological distress, not all the specific symptoms of psychological distress could be screened out. Some more specialized scales, such as Hamilton Depression Rating Scale, may be further needed to assess emotional symptoms in $\mathrm{MOH}$ patients if it is possible during the pandemic.
Several limitations should be noted in our study. Firstly, this study was based on a relatively small sample of $78 \mathrm{MOH}$ patients from a single center, which may be difficult to recruit sufficient subjects to provide convincing results as multiple centers. Whereas, the prevalence of $\mathrm{MOH}$ in the general population is $1 \%$ to $2 \%$ [9] and $\mathrm{MOH}$ is a secondary disease which may be neglected by many physicians who do not specialize in headache. Timely follow-up for the drug use and standard management of $\mathrm{MOH}$ in many other medical centers are lacking. Multi-center study with large sample on $\mathrm{MOH}$ patients will be further conducted if $\mathrm{MOH}$ could be better concerned and the management could be standardized under the regular epidemic prevention and control of COVID-19. On the other hand, West China Hospital, the core provider for medical sources in southwestern China, is a large tertiary medical center with abundant and representative sample of patients and we have a professional headache team to recognize those $\mathrm{MOH}$ patients. The participants in our study were still a representative group of $\mathrm{MOH}$ and the results were 
Table 5 Univariate and multivariate logistic analysis to identify independent variables decreasing days with acute medication

\begin{tabular}{|c|c|c|c|c|}
\hline \multirow[t]{2}{*}{ Variables } & \multicolumn{2}{|l|}{ Univariate } & \multicolumn{2}{|l|}{ Multivariate } \\
\hline & $\mathrm{OR}(95 \% \mathrm{Cl})$ & $\mathbf{P}$ & OR(95\%Cl) & $\mathbf{P}$ \\
\hline Sex, male & $3.42(1.21-9.67)$ & $0.021^{*}$ & $4.78(1.44-15.87)$ & $0.011^{*}$ \\
\hline Age, year & $1.01(0.97-1.06)$ & 0.581 & - & - \\
\hline Marital status, married & $1.51(0.16-14.33)$ & 0.720 & - & - \\
\hline Education level (> 12 years) & $1.11(0.31-4.00)$ & 0.878 & - & - \\
\hline Household income monthly & $1.71(0.62-4.69)$ & 0.300 & - & - \\
\hline Preexisting headache diagnoses (CTTH vs. others) & $1.25(0.46-3.42)$ & 0.663 & - & - \\
\hline Duration of medication overuse & $0.96(0.87-1.05)$ & 0.336 & $0.96(0.88-1.05)$ & 0.359 \\
\hline Available access to regular prophylactic medication & $2.47(0.89-6.85)$ & 0.083 & $2.31(0.63-8.43)$ & 0.206 \\
\hline Following abrupt withdrawal & $1.63(0.59-4.45)$ & 0.344 & $2.82(0.67-11.91)$ & 0.160 \\
\hline Headache intensity per month in the pre-pandemic 3 months period & $1.07(0.86-1.34)$ & 0.535 & $1.04(0.79-1.38)$ & 0.780 \\
\hline Days per month with acute medication in the pre-pandemic 3 months period & $1.04(0.99-1.08)$ & 0.127 & $1.05(0.99-1.11)$ & 0.131 \\
\hline History of epidemiological area exposure & $0.36(0.02-5.98)$ & 0.474 & - & - \\
\hline Suspected COVID-19 cases themselves or in their relatives & - & 1.000 & - & - \\
\hline COVID-19 cases in respondent's residential community & $0.36(0.02-5.98)$ & 0.474 & - & - \\
\hline Level of concern about COVID-19 pandemic & $0.68(0.42-1.12)$ & 0.132 & - & - \\
\hline Duration spent on following news of pandemic, hours per day & $1.10(0.71-1.71)$ & 0.656 & - & - \\
\hline Feel of difficulty in controlling emotion during the COVID-19 pandemic & $1.40(0.24-8.24)$ & 0.714 & - & - \\
\hline Stressors total score during the COVID-19 pandemic & $1.00(0.96-1.06)$ & 0.866 & - & - \\
\hline Fear for getting COVID-19 & $0.94(0.80-1.12)$ & 0.505 & - & - \\
\hline Physical and psychological distress caused by isolation & $0.98(0.74-1.28)$ & 0.863 & $0.93(0.67-1.29)$ & 0.664 \\
\hline Inconvenience caused by work and life changes & $1.00(0.83-1.21)$ & 0.979 & $1.10(0.87-1.39)$ & 0.426 \\
\hline Social discrimination & - & 0.999 & - & - \\
\hline Limited social function & $1.05(0.93-1.18)$ & 0.430 & - & - \\
\hline Economic losses & $1.06(0.87-1.29)$ & 0.591 & - & - \\
\hline Coronavirus death of family members or friends & - & 1.000 & - & - \\
\hline Kessler 6-item psychological distress scale during the COVID-19 pandemic & $1.07(0.89-1.29)$ & 0.497 & - & - \\
\hline
\end{tabular}

$C l$ Confidence interval; *: Statistically significant at $P<0.05$

definitely reliable. Secondly, some data, such as psychological distress and COVID-19 related stressor, were difficult to collect and were dependent on self-reports. The information may vary with the status, educational level and personality of the individual who response to it. These might result in risk of bias. Considering these, we chose the classic published scales to design the questionnaire and items in the questionnaire were relatively typical and representative. Finally, a considerable number of patients could not complete the questionnaire online on the electronic device, so in this study we uniformly used telephone interview to complete the survey. It might also lead to the risk of bias for information collection, such as some self-rating scale (eg. K-6). We will continuously observe the psychosocial status and outcome of $\mathrm{MOH}$ patients with specialized scales and long-term follow-up to provide more clinical evidence in guiding peri- $\mathrm{MOH}$ management.

\section{Conclusions}

Our findings reflect that $\mathrm{MOH}$ patients experienced a worse relief of headache symptoms and drug withdrawal during the pandemic. Available access to regular prophylactic medications was the significant independent factor for improvement of headache symptoms. Following abrupt withdrawal and high educational level were both significant factors for decreased headache intensity. Male sex was significantly associated with decreased days with acute medication. Headache specialists should give more awareness to education and counselling for $\mathrm{MOH}$ patients in the long-term fight against COVID-19 pandemic.

\section{Abbreviations}

COVID-19: Coronavirus disease 2019; SARS-CoV-2: Severe acute respiratory syndrome coronavirus 2; MOH: Medication overuse headache; ICHD-III: The International Classification of Headache Disorders, 3rd edition; TTH: Tension- 
type headache; MIDAS: Migraine Disability Assessment Scale; K-6: Kessler 6item; SPSS: Statistical Product and Service Solutions

\section{Acknowledgments}

We thank all participants for their willingness to participate in this study.

\section{Authors' contributions}

CLL and YBL analyzed the data, drafted and revised the manuscript and they contributed equally to this work. MMM, YZ, JJB, WJG, YQL and CP were responsible for collecting data and drafting the manuscript. $\mathrm{LH}$ designed the study and drafted the manuscript. All authors read and approved the final manuscript.

\section{Funding}

This project was supported by the "1.3.5 Project for Disciplines of Excellence of West China Hospital, Sichuan University" (grant number: ZY2016203) and "Project funded by China Postdoctoral Science Foundation" (grant number:2020 M673248)

\section{Availability of data and materials}

Not applicable. The datasets of this current study are not available to public. Anonymous data can be obtained from the corresponding author upon appropriate request.

\section{Declarations}

\section{Ethics approval and consent to participate}

The study was approved by the Ethics Committee of West China Hospital, Sichuan University, and verbal informed consent was provided by all participants.

\section{Consent for publication}

Consent to publish had been obtained from all the subjects.

\section{Competing interests}

The authors declare that they have no competing interests.

Received: 8 March 2021 Accepted: 10 May 2021

Published online: 21 May 2021

\section{References}

1. Coronaviridae Study Group of the International Committee on Taxonomy of Viruses (2020) The species severe acute respiratory syndrome-related coronavirus: classifying 2019-nCoV and naming it SARS-CoV-2. Nat Microbiol 5(4):536-544. https://doi.org/10.1038/s41564-020-0695-z

2. Holshue ML, DeBolt C, Lindquist S, Lofy KH, Wiesman J, Bruce H, Spitters C, Ericson K, Wilkerson S, Tural A, Diaz G, Cohn A, Fox L, Patel A, Gerber SI, Kim L, Tong S, Lu X, Lindstrom S, Pallansch MA, Weldon WC, Biggs HM, Uyeki TM, Pillai SK, Washington State 2019-nCoV Case Investigation Team (2020) First case of 2019 novel coronavirus in the United States. N Engl J Med 382(10):929-936. https://doi.org/10.1056/NEJMoa2001191

3. Wang FS, Zhang C (2020) What to do next to control the 2019-nCoV epidemic? Lancet. 395(10222):391-393. https://doi.org/10.1016/S0140-6736(2 0)30300-7

4. Chan KW, Wong VT, Tang SCW (2020) COVID-19: an update on the epidemiological, clinical, preventive and therapeutic evidence and guidelines of integrative Chinese-Western medicine for the management of 2019 novel coronavirus disease. Am J Chin Med 48(3):737-762. https://doi. org/10.1142/S0192415X20500378

5. Mahase E (2020) Covid-19: WHO declares pandemic because of "alarming levels" of spread, severity, and inaction. Bmj. 368:m1036

6. World Health Organization. Weekly epidemiological update-29 December 2020. 2020. https://www.who.int/publications/m/item/weeklyepidemiological-update\%2D\%2D-29-december-2020. Accessed 10 Jan 2021.

7. Zhou J, Liu L, Xue P, Yang X, Tang X (2020) Mental health response to the COVID-19 outbreak in China. Am J Psychiatry 177(7):574-575. https://doi. org/10.1176/appi.ajp.2020.20030304

8. Bhaskar S, Bradley S, Israeli-Korn S, Menon B, Chattu VK, Thomas P, Chawla J, Kumar R, Prandi P, Ray D, Golla S, Surya N, Yang H, Martinez S, Ozgen MH, Codrington J, González EMJ, Toosi M, Hariya Mohan N, Menon KV, Chahidi A, Mederer Hengstl S (2020) Chronic neurology in COVID-19 era: clinical considerations and recommendations from the REPROGRAM consortium. Front Neurol 11:664. https://doi.org/10.3389/fneur.2020.00664

9. Diener HC, Dodick D, Evers S, Holle D, Jensen RH, Lipton RB, Porreca F, Silberstein S, Schwedt T (2019) Pathophysiology, prevention, and treatment of medication overuse headache. Lancet Neurol 18(9):891-902. https://doi. org/10.1016/S1474-4422(19)30146-2

10. Diener HC, Antonaci F, Braschinsky M, Evers S, Jensen R, Lainez M, Kristoffersen ES, Tassorelli C, Ryliskiene K, Petersen JA (2020) European academy of neurology guideline on the management of medicationoveruse headache. Eur J Neurol 27(7):1102-1116. https://doi.org/10.1111/ ene.14268

11. Vandenbussche N, Laterza D, Lisicki M, Lloyd J, Lupi C, Tischler H, Toom K, Vandervorst F, Quintana S, Paemeleire K, Katsarava Z (2018) Medicationoveruse headache: a widely recognized entity amidst ongoing debate. J Headache Pain. 19(1):50. https://doi.org/10.1186/s10194-018-0875-x

12. GBD 2015 Disease and Injury Incidence and Prevalence Collaborators. Global, regional, and national incidence, prevalence, and years lived with disability for 310 diseases and injuries, 1990-2015: a systematic analysis for the Global Burden of Disease Study 2015. Lancet. 2016;388(10053):1545602. https://doi.org/10.1016/S0140-6736(16)31678-6.

13. Linde M, Gustavsson A, Stovner LJ, Steiner TJ, Barré J, Katsarava Z, Lainez JM, Lampl C, Lantéri-Minet M, Rastenyte D, Ruiz de la Torre E, Tassorelli C, Andrée C (2012) The cost of headache disorders in Europe: the Eurolight project. Eur J Neurol 19(5):703-711. https://doi.org/10.1111/j.1468-1331.2011. 03612.x

14. Bendtsen L, Munksgaard S, Tassorelli C, Nappi G, Katsarava Z, Lainez M, Leston JA, Fadic R, Spadafora S, Stoppini A, Jensen R, the COMOESTAS Consortium (2014) Disability, anxiety and depression associated with medication-overuse headache can be considerably reduced by detoxification and prophylactic treatment. Results from a multicentre, multinational study (COMOESTAS project). Cephalalgia. 34(6):426-433. https://doi.org/10.1177/0333102413515338

15. D'Amico D, Grazzi L, Curone M et al (2015) Difficulties in work activities and the pervasive effect over disability in patients with episodic and chronic migraine. Neurol Sci 36(Suppl 1):9-11. https://doi.org/10.1007/s10072-01 5-2130-4

16. Jelinski SE, Magnusson JE, Becker WJ (2007) Factors associated with depression in patients referred to headache specialists. Neurology. 68(7): 489-495. https://doi.org/10.1212/01.wnl.0000253183.57001.b3

17. Bottiroli S, Allena M, Sances G, de Icco R, Avenali M, Fadic R, Katsarava Z, Lainez MJA, Goicochea MT, Bendtsen L, Jensen RH, Nappi G, Tassorelli C, the COMOESTAS Consortium (2019) Psychological, clinical, and therapeutic predictors of the outcome of detoxification in a large clinical population of medication-overuse headache: a six-month follow-up of the COMOESTAS project. Cephalalgia. 39(1):135-147. https://doi.org/10.1177/033310241 8783317

18. Krymchantowski AV, Barbosa JS (2000) Prednisone as initial treatment of analgesic-induced daily headache. Cephalalgia. 20(2):107-113. https://doi. org/10.1046/j.1468-2982.2000.00028.x

19. Lipton RB, Stewart WF (1998) Migraine headaches: epidemiology and comorbidity. Clin Neurosci 5(1):2-9

20. Radat F, Sakh D, Lutz G, Amrani ME, Ferreri M, Bousser MG (1999) Psychiatric comorbidity is related to headache induced by chronic substance use in migraineurs. Headache. 39(7):477-480. https://doi.org/10.1046/j.1526-4610.1 999.3907477.x

21. Mitsikostas DD, Thomas AM (1999) Comorbidity of headache and depressive disorders. Cephalalgia. 19(4):211-217. https://doi.org/10.1046/j.14 68-2982.1999.019004211.x

22. Radat F, Creac'h C, Swendsen JD, Lafittau M, Irachabal S, Dousset V, Henry P (2005) Psychiatric comorbidity in the evolution from migraine to medication overuse headache. Cephalalgia. 25(7):519-522. https://doi.org/10.1111/j.14 68-2982.2005.00910.x

23. Szperka CL, Ailani J, Barmherzig R, Klein BC, Minen MT, Halker Singh RB, Shapiro RE (2020) Migraine Care in the era of COVID-19: clinical pearls and Plea to insurers. Headache. 60(5):833-842. https://doi.org/10.1111/head.13810

24. Al-Hashel JY, Ismail II (2020) Impact of coronavirus disease 2019 (COVID-19) pandemic on patients with migraine: a web-based survey study. J Headache Pain 21(1):115. https://doi.org/10.1186/s10194-020-01183-6

25. Headache Classification Committee of the International Headache Society. The International Classification of Headache Disorders, 3rd edition. Cephalalgia. 2018;38(1):1-211. https://doi.org/10.1177/0333102417738202. 
26. Kang YK, Guo WJ, Xu H, Chen YH, Li XJ, Tan ZP, Li N, Gesang ZR, Wang YM, Liu CB, Luo Y, Feng J, Xu QJ, Lee S, Li T (2015) The 6-item Kessler psychological distress scale to survey serious mental illness among Chinese undergraduates: psychometric properties and prevalence estimate. Compr Psychiatry 63:105-112. https://doi.org/10.1016/j.comppsych.2015.08.011

27. Kessler RC, Andrews G, Colpe $L$ et al (2002) Short screening scales to monitor population prevalences and trends in non-specific psychological distress. Psychol Med 32(6):959-976. https://doi.org/10.1017/S0033291702 006074

28. Kessler RC, Green JG, Gruber MJ et al (2010) Screening for serious mental illness in the general population with the $\mathrm{K} 6$ screening scale: results from the WHO World Mental Health (WMH) survey initiative. Int J Methods Psychiatr Res 19 Suppl 1(Suppl 1):4-22

29. Wittchen HU (2010) Screening for serious mental illness: methodological studies of the K6 screening scale. Int J Methods Psychiatr Res 19 Suppl 1(Suppl 1):1-3

30. Zeeberg P, Olesen J, Jensen R (2005) Efficacy of multidisciplinary treatment in a tertiary referral headache Centre. Cephalalgia. 25(12):1159-1167. https:// doi.org/10.1111/j.1468-2982.2005.00980.x

31. Carlsen LN, Munksgaard SB, Nielsen M, Engelstoft IMS, Westergaard ML,

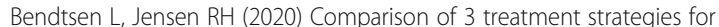
medication overuse headache: a randomized clinical trial. JAMA Neurol 77(9):1069-1078. https://doi.org/10.1001/jamaneurol.2020.1179

32. Dong Z, Chen X, Steiner TJ, Hou L, di H, He M, Dai W, Pan M, Zhang M, Liu R, Yu S (2015) Medication-overuse headache in China: clinical profile, and an evaluation of the ICHD-3 beta diagnostic criteria. Cephalalgia. 35(8):644-651. https://doi.org/10.1177/0333102414552533

33. World Health Organization. Preliminary results: rapid assessment of service delivery for noncommunicable diseases during the COVID-19 pandemic. 2020. https://www.who.int/who-documents-detail/rapid-assessment-ofservice-delivery-for-ncds-during-the-covid-19-pandemic. Accessed 10 Jan 2021.

34. Tassorelli C, Jensen R, Allena M, de Icco R, Katsarava Z, Miguel Lainez J, Leston JA, Fadic R, Spadafora S, Pagani M, Nappi G, the COMOESTAS Consortium (2017) The added value of an electronic monitoring and alerting system in the management of medication-overuse headache: a controlled multicentre study. Cephalalgia. 37(12):1115-1125. https://doi. org/10.1177/0333102416660549

35. Tassorelli $C$, Jensen R, Allena M, de Icco R, Sances G, Katsarava Z, Lainez M, Leston JA, Fadic R, Spadafora S, Pagani M, Nappi G, the COMOESTAS Consortium (2014) A consensus protocol for the management of medication-overuse headache: evaluation in a multicentric, multinational study. Cephalalgia. 34(9):645-655. https://doi.org/10.1177/0333102414521 508

36. Chiang CC, Schwedt TJ, Wang SJ, Dodick DW (2016) Treatment of medication-overuse headache: a systematic review. Cephalalgia. 36(4):371386. https://doi.org/10.1177/0333102415593088

37. Carlsen LN, Munksgaard SB, Jensen RH, Bendtsen L (2018) Complete detoxification is the most effective treatment of medication-overuse headache: a randomized controlled open-label trial. Cephalalgia. 38(2):225236. https://doi.org/10.1177/0333102417737779

38. Jonsson P, Linde M, Hensing G, Hedenrud T (2012) Sociodemographic differences in medication use, health-care contacts and sickness absence among individuals with medication-overuse headache. J Headache Pain. 13(4):281-290. https://doi.org/10.1007/s10194-012-0432-y

39. Trucco M, Meineri P, Ruiz L, Gionco M (2010) Medication overuse headache: withdrawal and prophylactic therapeutic regimen. Headache. 50(6):989-997. https://doi.org/10.1111/j.1526-4610.2010.01631.x

40. Engelstoft IMS, Carlsen LN, Munksgaard SB, Nielsen M, Jensen RH, Bendtsen $L$ (2019) Complete withdrawal is the most feasible treatment for medication-overuse headache: a randomized controlled open-label trial. Eur J Pain 23(6):1162-1170. https://doi.org/10.1002/ejp.1383

41. PeConga EK, Gauthier GM, Holloway A et al (2020) Resilience is spreading: mental health within the COVID-19 pandemic. Psychol Trauma 12(S1):S47Ss8. https://doi.org/10.1037/tra0000874

42. McKay D, Asmundson GJG (2020) Substance use and abuse associated with the behavioral immune system during COVID-19: the special case of healthcare workers and essential workers. Addict Behav 110:106522. https:// doi.org/10.1016/j.addbeh.2020.106522
43. Horesh D, Brown AD (2020) Traumatic stress in the age of COVID-19: a call to close critical gaps and adapt to new realities. Psychol Trauma 12(4):331335. https://doi.org/10.1037/tra0000592

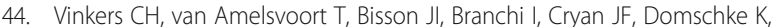
Howes OD, Manchia M, Pinto L, de Quervain D, Schmidt MV, van der Wee NJA (2020) Stress resilience during the coronavirus pandemic. Eur Neuropsychopharmacol 35:12-16. https://doi.org/10.1016/j.euroneuro.2020. 05.003

45. Riehm KE, Brenneke SG, Adams LB et al (2020) Association between psychological resilience and changes in mental distress during the COVID19 pandemic. J Affect Disord 282:381-385

46. Gao J, Zheng P, Jia Y, Chen H, Mao Y, Chen S, Wang Y, Fu H, Dai J (2020) Mental health problems and social media exposure during COVID-19 outbreak. PLoS One 15(4):e0231924. https://doi.org/10.1371/journal.pone. 0231924

\section{Publisher's Note}

Springer Nature remains neutral with regard to jurisdictional claims in published maps and institutional affiliations.

\section{Ready to submit your research? Choose BMC and benefit from:}

- fast, convenient online submission

- thorough peer review by experienced researchers in your field

- rapid publication on acceptance

- support for research data, including large and complex data types

- gold Open Access which fosters wider collaboration and increased citations

- maximum visibility for your research: over $100 \mathrm{M}$ website views per year

At BMC, research is always in progress.

Learn more biomedcentral.com/submissions 